\title{
Reações da espécie invasora Achatina fulica (Mollusca: Achatinidae) à fatores abióticos: perspectivas para o manejo
}

\begin{abstract}
Marta Luciane Fischer
${ }^{1}$ Núcleo de Estudos do Comportamento Animal, Departamento de Biologia, Pontifícia Universidade Católica do Paraná. Avenida Silva Jardim 1664/1101, 80250-200 Curitiba, Paraná, Brasil. E-mail: nephilla@terra.com.br

ABSTRACT. Reactions of the invasive alien species Achatina fulica to abiotic factors: perspectives for the management. Achatina fulica Bowdich, 1822 is an african snail that is invasive in different parts of the world, being characterized mainly by its high adaptability. Our objective was to evaluate the influence of abiotic factors, such as temperature and substrate, on the egg eclosion, adult and juvenile reaction to different abiotics factors, and the resistance of $A$. fulica to popular methods of control. Three studies were made, including 19 laboratory experiments and observations of free animals in the municipal district of Guaraqueçaba, southern Brazil. Eggs were characterized as the most fragile phase, whereas the juveniles and adults were resistant to the immersion in fresh and salt water and little resistant to temperature variation and salt, using burying, aestivation, and muscular force as defense strategies. Those strategies should be considered in management actions and in orientating popular methods of control.
\end{abstract}

KEY WORDS. Aestivation; exotic invasive species; giant african snail; Guaraqueçaba; resistance.

O caramujo Achatina fulica Bowdich, 1822 é originário do leste da África, onde evoluiu nas margens de florestas (RAut \& BARKer 2002). Através do seu uso comercial, essa espécie tornou-se uma das cem piores espécies invasoras do mundo (Alowe et al. 2004). A presença desse caramujo, principalmente em áreas urbanas (Simiño \& Fischer 2004, Fischer \& Colley 2005), resulta em impactos ambientais, econômicos e de saúde pública em várias regiões do mundo (RAUT \& BARKER 2002), inclusive no Brasil (Teles \& Fontes 1998).

O potencial invasor de $A$. fulica está associado às estratégias de defesa contra condições ambientais desfavoráveis, fato que dificulta o manejo e controle desses animais. Dentre esses mecanismos tem-se a estratégia reprodutiva, o hábito de se enterrar, a estivação e a produção do epifragma (RAUT \& BARKER 2002). Como estratégia reprodutiva, a espécie alia o hermafroditismo, cópula simultânea e produção de centenas de ovos de pequena alocação de energia (Toмiуama 1996) que podem ser liberados ao meio faltando poucos dias para eclosão (RAUT \& BARKer 2002). Esses caramujos fazem covas com até 25 $\mathrm{cm}$ de profundidade, cavando com a porção anterior da massa cefalopediosa. Eles podem ficar totalmente enterrados e, conforme ovipositam, vão saindo. Portanto, os ovos estarão presentes da base até a abertura da cova, sendo que os mais superficiais protegem os mais profundos (RAUT \& BARKER 2002). Esses caramujos, durante o dia, ficam enterrados ou suspensos em caules de árvores ou outros substratos como, por exemplo, muros e paredes de casas (Fischer \& Colley 2004). Em ambas as situações, os animais podem produzir o epifragma, que é uma estrutura calcificada que previne a desidratação (D'Ávila et al.
2004). Em regiões com estações bem definidas os animais estivam durante o período mais seco (Hodası 1979). Nessas situações, ocorre uma aparente diminuição da população, que volta a ficar ativa nos períodos úmidos (Fischer \& Colley 2005). Apesar de ser reconhecida a grande resistência e alta adaptabilidade de $A$. fulica, são poucos os trabalhos que quantificaram e classificaram experimentalmente as estratégias adotadas pela espécie (RAut \& Barker 2002). Dentre esses estudos, Raut \& CHOSE $(1977,1981)$ avaliaram os fatores relacionados com a mortalidade durante o período de estivação. A ausência dessas informações impossibilitou o sucesso das tentativas de controle e/ou extermínio da $A$. fulica, as quais datam de cerca de um século. Diversas técnicas, desde barreiras físicas, agentes químicos e coleta manual foram utilizadas. O uso de controle biológico foi o que causou mais danos do que o próprio gastrópode (Civerrel \& Simberloff 1996, Raut \& Barker 2002). Apesar da invasão do caramujo africano ser um problema que precisa de intervenção rápida, para que as ações de manejo sejam eficazes, é necessário prioritariamente conhecer-se as reações da espécie a fatores abióticos bem como suas estratégias de defesa. Desta forma, o presente estudo teve como objetivo avaliar a influência de fatores abióticos, tais como temperatura e substrato na eclosão dos ovos, a reação de jovens de adultos a diferentes fatores abióticos e a resistência de $A$. fulica a métodos populares de controle.

\section{MATERIAL E MÉTODOS}

Os animais utilizados foram coletados em terrenos baldios do município de Guaraqueçaba, litoral norte do Paraná $\left(25^{\circ} 18^{\prime} 24^{\prime \prime}\right.$ S e $\left.48^{\circ} 19^{\prime} 44^{\prime \prime} \mathrm{W}\right)$ durante o verão de $2002 / 2003$ e 
mantidos no Núcleo de Estudos do Comportamento Animal, Pontifícia Universidade Católica do Paraná (NEC-PUCPR) em terrários de 100 l. O fornecimento de alimento a base de vegetais e a manutenção dos terrários foram realizados duas vezes por semana. A fim de contemplar diferentes estágios ontogenéticos, os estudos foram conduzidos com ovos e três classes de tamanho: pequenos, de 1 a $4 \mathrm{~cm}$ de comprimento de concha, médios de 4 a $7 \mathrm{~cm}$ e grandes, com mais de $8 \mathrm{~cm}$.

Para avaliar a freqüência de eclosão dos ovos de A. fulica foram utilizados aleatoriamente 4608 ovos originários de cinqüenta posturas de laboratório e realizados três experimentos: influência da temperatura, do substrato e da profundidade de enterramento. 1) Para avaliação da influência da temperatura, seis placas de Petri (12 cm de diâmetro) contendo 60 ovos sobre terra úmida foram mantidas durante três meses em diferentes condições térmicas. Devido à umidade do ar estar condicionada às temperaturas nos equipamentos utilizados (estufa: $15^{\circ}$ a $30^{\circ}$, geladeira: $4^{\circ}$ a $10^{\circ} \mathrm{C}$ e freezer: abaixo $4^{\circ} \mathrm{C}$ ) as mesmas foram monitoradas, mas não controladas. Assim, as temperaturas testadas e suas respectivas umidades relativas do ar foram: $-20^{\circ} \mathrm{C}$ e $0 \%,-5^{\circ}$ e $0 \%, 10^{\circ}$ e $87 \%, 15^{\circ}$ e $90 \%, 20^{\circ}$ e $81 \%$, $25^{\circ}$ e $76 \%$ e $30^{\circ}$ e $56 \%$. Como controle o mesmo número placas de Petri e de ovos foram mantidos em temperatura e umidade relativa do ar ambiente $\left(18-24^{\circ} \mathrm{C}\right.$ e $\left.75-91 \%\right)$. 2) Para avaliação da influência do substrato foram testadas: areia marinha, areia de rio e terra orgânica (controle), sob as condições úmida e seca. Os substratos foram colocados em uma placa de Petri (12 cm de diâmetro com seis réplicas) juntamente com 134 ovos sobre e $54 \mathrm{sob}(0,5 \mathrm{~cm}$ de profundidade). As placas foram mantidas em temperatura e umidade relativa do ar ambiente (18-24 ${ }^{\circ} \mathrm{C}$ e $\left.75-91 \%\right)$ e vistoriadas diariamente durante três meses. 3) Para avaliação da profundidade de enterramento na eclosão dos ovos e na capacidade de desenterramento dos recém-eclodidos, 150 ovos foram depositados em recipientes plásticos de $300 \mathrm{ml}$ (seis réplicas) e cobertos com uma camada de 1,3 e $6 \mathrm{~cm}$ de terra úmida. Utilizou-se como controle a mesma quantidade de ovos mantidos na superfície da terra. Os recipientes foram mantidos em temperatura e umidade relativa do ar ambiente $\left(18-24^{\circ} \mathrm{C}\right.$ e $\left.75-91 \%\right)$ e vistoriados diariamente durante três meses.

Para avaliação das estratégias de defesa da A. fulica contra os fatores abióticos foram avaliados os fatores desencadeadores da entrada e saída da estivação, enterramento e força muscular. Nos testes foram realizadas 30 réplicas para cada classe de tamanho e usado como controle os animais mantidos em condições de temperatura e umidade relativa do ar ambientes.

Estivação: os fatores que desencadeiam a estivação e produção de epifragma foram analisados através da realização de quatro experimentos. 1) Moluscos ativos (30 de cada classe de tamanho) mantidos individualizados em recipientes de $2000 \mathrm{ml}$ fechados, foram expostos por $24 \mathrm{~h}$ à diferentes condições térmicas, sendo avaliadas as seguintes temperaturas e umidades do ar correspondentes: $-5^{\circ} \mathrm{C}$ e $0 \%, 0^{\circ}$ e $0 \%, 4^{\circ}$ e $0 \%, 9^{\circ}$ e $87 \%, 13^{\circ}$ e
$89 \%, 17^{\circ}$ e $90 \%, 22^{\circ}$ e $78 \%$ e $35^{\circ}$ e $48 \%$ (controle: $17^{\circ} \mathrm{C}-24^{\circ} \mathrm{C}$ e $75-91 \%)$. Foram utilizados estufa: $15^{\circ}$ a $30^{\circ}$, geladeira: $4^{\circ}$ a $10^{\circ} \mathrm{C}$ e freezer: abaixo $4^{\circ} \mathrm{C}$, sendo os animais colocados diretamente na temperatura testada, sem passar por acréscimo ou decréscimo gradual. 2) Para avaliação da estivação associada ao enterramento foi acompanhada durante uma semana a produção de epifragma em 30 moluscos de cada classe de tamanho propositalmente enterrados ativos em terra orgânica úmida, a 5 cm de profundidade em um terrário de 90 1. 3) Comparativamente (= controle), durante cinco meses foi acompanhado o número de animais que estivaram ao enterrar-se espontaneamente no terrário de $90 \mathrm{l}$ contendo uma camada $30 \mathrm{~cm}$ de terra úmida, o qual foi mantido em condições de temperatura e umidade relativa do ar ambientes $\left(18-24^{\circ} \mathrm{C}\right.$ e $\left.75-91 \%\right)$. 4) O registro da estivação em animais livres foi procedido em substratos (vegetação, muro, entulhos e base de plantas e muros) presentes em quintais no ambiente urbano do município de Guaraqueçaba. Para tanto, foram conduzidas duas fases de campo diurnas, uma durante o verão e outra no inverno de 2004. Nas duas fases foram coletados e mensurados todos os caramujos encontrados em 11 terrenos sorteados a partir do mapa da cidade, sendo vistoriados os mesmos terrenos nas duas estações.

Os fatores que desencadeiam a saída do estado de estivação e conseqüente eliminação do epifragma foram analisados através da realização de cinco experimentos utilizando animais que estavam estivando de 5 a 10 dias. 1) Moluscos estivando (30 de cada classe de tamanho) acondicionados individualmente em recipientes de $2000 \mathrm{ml}$ fechados foram expostos durante $24 \mathrm{~h}$ às seguintes temperaturas e suas respectivas umidades do ar correspondentes: $9^{\circ}$ e $87 \%, 17^{\circ}$ e $90 \%, 20^{\circ}$ e $81 \%$, $25^{\circ}$ e $76 \%, 30^{\circ}$ e $56 \%$ e $35^{\circ}$ e $48 \%$ (controle: $17^{\circ} \mathrm{C}-24^{\circ} \mathrm{C}$ e $75-$ $91 \%)$. Foram utilizados estufa: $15^{\circ}$ a $30^{\circ}$, geladeira: $4^{\circ}$ a $10^{\circ} \mathrm{C} \mathrm{e}$ freezer: abaixo $4^{\circ} \mathrm{C}$, sendo os animais colocados diretamente na temperatura testada, sem passar por acréscimo ou decréscimo gradual. 2). Para influência dos alimentos como estímulo, 85 moluscos estivando (réplica $=33$ pequenos, 31 médios e 21 grandes) foram colocados na presença de repolho, couve, alface, espinafre e vegetais em putrefação. $\mathrm{O}$ animal estivando permaneceu junto com cada alimento por 24 h, sendo substituídos a cada teste. 3) Para avaliação da influência da umidade foi borrifada água $(30 \mathrm{ml}$ ) em 85 moluscos estivando (réplica $=33$ pequenos, 31 médios e 21 grandes) e os mesmos observados por 12 h. 4) 30 animais em estivação de cada classe de tamanho foram submergidos em um aquário com 16 l de água potável à $21^{\circ} \mathrm{C}$, sendo monitorados por $12 \mathrm{~h}$. 5). A ação do cloreto de sódio sobre 10 moluscos em estivação foi analisada depositando $5 \mathrm{~g}$ de sal sobre toda a área do epifragma de dez animais, sendo os mesmos acompanhados por $24 \mathrm{~h}$.

Enterramento: a freqüência, profundidade e tempo de enterramento da $A$. fulica foram avaliadas em 30 animais de cada classe de tamanho. A freqüência e tempo de desenterramento foram verificados ao enterrar, propositalmente 30 moluscos grandes e 30 médios a $16 \mathrm{~cm}$, e 30 pequenos a $9 \mathrm{~cm}$ 
de profundidade. Ambos os experimentos foram conduzidos em um terrário de $90 \mathrm{l}$ contendo uma camada $30 \mathrm{~cm}$ de terra úmida, mantido em condições de temperatura e umidade do ar ambientes $\left(18-24^{\circ} \mathrm{C}\right.$ e $\left.75-91 \%\right)$. Os experimentos foram conduzidos durante uma semana e diariamente era registrada a localização e a profundidade dos animais. Para detecção da profundidade de enterramento foi fixado um barbante de $10 \mathrm{~cm}$ na parte superior da concha do caramujo.

Força muscular: para determinar a força muscular de $A$. fulica considerou-se o deslocamento com diferentes pesos: 1) na posição horizontal e 2) o peso suportado na posição vertical. Após a mensuração do comprimento da concha, pesagem e verificação do deslocamento sobre uma superfície lisa (controle), foram fixados chumbo de pescaria (5-500 g) sobre a concha de 30 animais de cada classe de tamanho. Ocorrendo o deslocamento dentro de vinte minutos, eram adicionados mais pesos, até que o animal não se deslocasse mais nesse período, considerando, então, o valor do último peso. Na avaliação vertical, considerou-se o peso que o animal suportou sem cair ou escorregar da parede de uma caixa de plástico.

Geralmente os moradores de uma região com o caramujo invasor ficam penalizados em sacrificá-los. Então, adotam como método de controle o ato de atirá-los em rios ou mar, acreditando que morram afogados imediatamente (Fischer \& COLLEY 2004). Partindo da suposição que esses animais são resistentes ao meio aquático, 30 caramujos de cada classe de tamanho foram colocados em um aquário contendo 161 de água potável e 30 em outro aquário contendo 161 com água salobra da Baía de Guaraqueçaba (salinidade entre 11,2 e 18,4). Durante $24 \mathrm{~h}$ foram quantificados os moluscos que conseguiam sair da água pelas paredes do recipiente, sendo o monitoramento ininterrupto nas primeiras cinco horas.

Em Guaraqueçaba os moradores geralmente depositam sal ao redor das casas, essa prática é fundamentada na premissa de que o sal evita que os caramujos subam nas paredes e que entrem nas casas (FIscher \& Colley 2004). Assim elaborou-se de um experimento com 30 moluscos de cada classe de tamanho, os quais foram postos um a um em um círculo formado com cloreto de sódio, com $30 \mathrm{~cm}$ de raio e $1 \mathrm{~cm}$ de espessura. Foi verificada a possível passagem pelo sal e sua conseqüência. Como controle foi observado o deslocamento prévio dos animais pelo substrato.

Outra forma de controle popular é a colocação de muitos animais em um saco plástico e a deposição de pequenas quantidades de sal. Porém, o relato de moradores de que alguns animais saem ilesos, levou ao questionamento se apenas uma pequena quantidade de sal cair sobre o corpo do animal, seria suficiente para matá-lo. Assim, a mesma quantidade de animais do experimento anterior foi utilizada para verificar sua sobrevivência ao colocar $5 \mathrm{~g}$ de cloreto de sódio na região anterior do pé de animais ativos.

Os valores relativos às freqüências foram analisados utilizando o teste qui-quadrado, sendo considerado como va- lor esperado os resultados obtidos nos controles. Também foi utilizado esse teste para comparação dos resultados obtidos entre as três classes de tamanho. A relação entre número de animais que saíram da estivação e a temperatura foi obtida através do teste de regressão linear. A comparação do peso suportado para o deslocamento vertical e horizontal foi avaliada através dos testes paramétricos ANOVA com teste a posteriori Tuckey. Nos testes múltiplos, os valores de probabilidade foram ajustados de correção de Bonferroni.

O presente projeto foi desenvolvido segundo a legislação vigente no país, possuindo licença para captura e transporte dos animais emitido pelo IBAMA-PR e aval do Comitê de Ética no Uso de Animais da PUCPR. Espécimes testemunho foram depositados na coleção científica do Museu de Zoologia, PUCPR sob o número de tombo 11611.

\section{RESULTADOS}

\section{Influência da temperatura e do substrato na eclosão dos ovos}

Em nenhuma das temperaturas as quais os ovos foram submetidos experimentalmente ocorreram eclosões; a percentagem de eclosão dos ovos mantidos em temperatura ambiente foi de $45,8 \%$. A natureza do substrato, a umidade e a localização dos ovos foram fatores importantes na determinação da eclosão. A maioria significativa das eclosões ocorreu no grupo controle, ou seja, nos ovos depositados sobre a terra úmida $\left(\chi_{(4)}^{2}=265\right.$; $\mathrm{p}<0,001)$, porém, apesar da baixa freqüência, foi registrada eclosão dos ovos depositados sobre todos os substratos que mantiveram-se úmidos, inclusive na areia do mar, sendo este o único substrato que não apresentou eclosões quando seco (Fig. 1). No entanto, foi obtida baixa freqüência de eclosão nos ovos cobertos pelos substratos, ocorrendo apenas em terra e areia de rio úmidas (Fig. 1). As eclosões dos ovos enterrados a 1 e $3 \mathrm{~cm}$ de profundidade (46\% e 40,6\% de eclosão) não diferiram dos deixa-

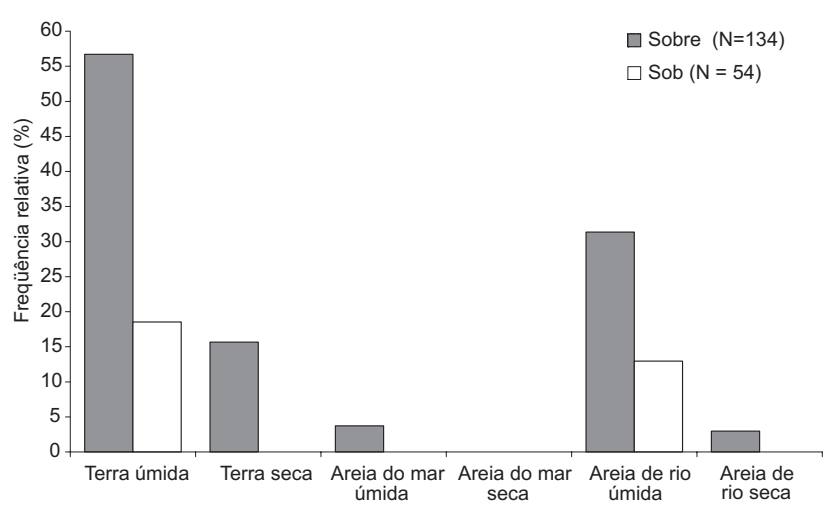

Figura 1. Freqüência relativa de eclosões de ovos de $A$. fulica incubados sobre e sob terra, areia do mar e areia do rio umidas e secas. As diferenças significativas $(p<0,05)$ estão representadas pelo asterisco $\left(^{*}\right)$. 
dos na superfície $(44 \%)$, porém ocorreram significativamente menos eclosões nos ovos enterrados a $6 \mathrm{~cm}(29,3 \%)\left(\chi_{(2)}^{2}=7,8\right.$; $\mathrm{p}<0,05)$. No período de duas semanas após a eclosão, nenhum recém-eclodido conseguiu desenterrar-se, independente das profundidades nas quais os ovos foram enterrados.

\section{Estratégias de defesa contra fatores abióticos}

As diferentes temperaturas testadas não desencadearam a produção do epifragma, sendo registrada a morte dos moluscos em baixas temperaturas $\left(-5^{\circ}, 0^{\circ}\right.$ e $\left.4^{\circ} \mathrm{C}\right)$. O enterramento induzido estimulou a entrada de estivação nos caramujos pequenos $(83 \%)\left(\chi_{(1)}^{2}=15 ; p<0,01\right)$. Nos médios foi registrado número semelhante de animais que estivaram (40\%) e que não estivaram (50\%). Dentre os caramujos grandes (13\%), a maioria significativa não estivou (87\%) $\left(\chi_{(1)}^{2}=16,1 ; p<0,01\right)$. Todavia, a estivação ocorreu na maioria significativa dos caramujos, independente do tamanho, que se enterraram espontaneamente (pequenos: 50, médios: 37 e grandes: 38$)\left(\chi_{(1)}^{2}=88,2 ; p<0,01\right)$. Em Guaraqueçaba, no verão, dos 852 animais amostrados nenhum estava estivando, ao contrário do inverno em que foi representado por 9\% dos 1077 animais coletados. O tamanho médio desses caramujos foi de 5,6 $\pm 2,6 \mathrm{~cm}(\mathrm{n}=101$; i.v. $=2,5-10)$, sendo representados por 36 , pequenos, 43 médios e 22 grandes, logo a estivação foi mais freqüente nos médios $\left(\chi_{(2)}^{2}=6,8\right.$; $\mathrm{p}<0,05)$. Os moluscos foram coletados estivando enterrados ( $\mathrm{n}=14)$, na vegetação $(\mathrm{n}=24)$ e em superfícies horizontais ( $\mathrm{n}$ $=23)$, porém predominaram em superfícies verticais $(\mathrm{n}=40)$ $\left(\chi_{(3)}^{2}=12,8 ; \mathrm{p}<0,01\right)$.

A saída do estado de estivação foi induzida por baixas temperaturas $\left(\mathrm{r}^{2}=0,93 ; \mathrm{F}=44,3 ; \mathrm{df}=1,3 ; \mathrm{p}<0,01\right)$, em proporções que não diferiram, em cada temperatura, entre as três classes de tamanho (Fig. 2). A saída de estivação em decorrência da presença de recursos alimentares apresentou relação com o tipo de alimento e o tamanho dos animais, ocorrendo principalmente nos grandes $\left(\chi_{(2)}^{2}=34,7 ; \mathrm{p}<0,01\right)$ e preferencialmente com espinafre $\left(\chi_{(3)}^{2}=23,1 ; \mathrm{p}<0,05\right)$ (Tab. I). Ao borrifar água diretamente sobre os animais em estivação, a maioria significativa não saiu de estivação (pequenos: 21,3\%, médios: 19,3\% e grandes: $9,5 \%)\left(\chi_{(2)}^{2}=35,6 ; p<0,01\right)$, porém a submersão em água doce estimulou a atividade em todos os animais. Ao ser

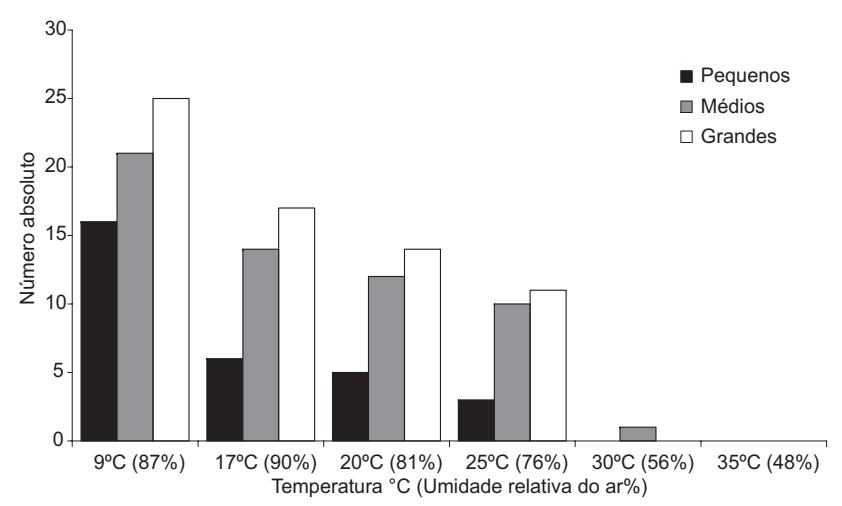

Figuras 2. Número absoluto de indivíduos de $A$. fulica pequenos, médios e grandes que saíram da estivação quando submetidos a diferentes temperaturas.

colocado sal sobre o epifragma de caramujos estivando, nenhum deles saiu da estivação e nenhum morreu.

O enterramento espontâneo foi freqüente nos animais pequenos (pequenos: 90\%, médios: $37 \%$ e grandes: $33 \%$ ) $\left(\chi_{(2)}^{2}=13,4 ; \mathrm{p}<0,01\right)$, dos quais a maioria se cobriu totalmente (70\%), enquanto a maioria dos animais medianos que se enterrou cobriu-se apenas parcialmente $(82 \%)\left(\chi_{(2)}^{2}=34,4 ; \mathrm{p}<0,01\right)$ e nos grandes a diferença não foi significativa (66\%). A profundidade média de enterramento foi $2,05 \pm 1,3 \mathrm{~cm}(\mathrm{n}=18$; i.v. $=$ $5-4)$ nos pequenos, $1,75 \pm 1,76 \mathrm{~cm}(\mathrm{n}=2$; i.v = 5-3) nos médios e $0,5 \mathrm{~cm}(\mathrm{n}=3)$ nos grandes. A maioria significativa dos animais que se enterrou, alcançou profundidades de até $0,5 \mathrm{~cm}$ (0,1-0,5 cm: 48\%, 0,51-2,5 cm: $12 \%, 0,26-3 \mathrm{~cm}: 24 \%, 0,31-0,35$ $\mathrm{cm}: 12 \%, 0,36-4 \mathrm{~cm}: 4 \%)\left(\chi_{(4)}^{2}=14,8 ; \mathrm{p}<0,01\right)$, sendo que o caramujo que se enterrou mais profundamente $(4 \mathrm{~cm})$ era pequeno. O tempo despendido para o enterramento, variou de um a seis dias (1 dia: 23,9\%, 2 dias: 10,4\%, 3 dias: 0, 4 dias: $39,5 \%, 5$ dias: $14,6 \%, 6$ dias: $12,5 \%$ ), sendo que a maioria demorou até 4 dias para se enterrar $\left(\chi_{(4)}^{2}=26\right.$; $\left.\mathrm{p}<0,01\right)$.

Ao ser enterrado experimentalmente, o desenterramento foi mais freqüente nos grandes (pequeno: 17\%, médios: $20 \%$, grandes: $37 \%)\left(\chi_{(2)}^{2}=13,1 ; \mathrm{p}<0,01\right)$, porém o número de cara-

Tabela I. Número absoluto de caramujos pequenos, médios e grandes que saíram do estado de estivação em decorrência da presença de espinafre, repolho, couve, alface e vegetais em putrefação.

\begin{tabular}{|c|c|c|c|c|c|c|c|c|}
\hline \multirow{2}{*}{ Alimentos } & \multicolumn{2}{|c|}{ Pequeno } & \multicolumn{2}{|c|}{ Médio } & \multicolumn{2}{|c|}{ Grande } & \multicolumn{2}{|c|}{ Total } \\
\hline & $\mathrm{N}$ & Saíram & $\mathrm{N}$ & Saíram & $\mathrm{N}$ & Saíram & $\mathrm{N}$ & Saíram \\
\hline Espinafre & 33 & 0 & 31 & 6 & 21 & 19 & 85 & 25 \\
\hline Repolho & 33 & 0 & 31 & 5 & 21 & 4 & 85 & 9 \\
\hline Couve & 33 & 0 & 31 & 0 & 21 & 3 & 85 & 3 \\
\hline Alface & 33 & 0 & 31 & 0 & 21 & 0 & 85 & 0 \\
\hline Putrefação & 33 & 0 & 31 & 0 & 21 & 0 & 85 & 0 \\
\hline Total & 165 & 0 & 155 & 11 & 105 & 26 & 425 & 37 \\
\hline
\end{tabular}


mujos que se desenterrou não diferiu dos que permaneceram enterrados. Já para os médios e pequenos foi mais freqüente permanecer enterrado $\left(\chi_{(2)}^{2}=14,5 ; \mathrm{p}<0,01\right)$. Os animais que foram enterrados levaram de um a sete dias para se desenterrarem (1 dia: 0, 2 dias: 27,3\%, 3 dias: 0, 4 dias: 50\%, 5 dias: 4,54\%, 6 dias: $4,54 \%, 7$ dias: 13,6$)$, sendo que a maioria despendeu até quatro dias $\left(\chi_{(6)}^{2}=32,4 ; \mathrm{p}<0,01\right)$.

Os caramujos suportaram, durante o deslocamento horizontal, até 1,2 vezes seu próprio peso, sendo que acima desse valor os animais se recolhiam na concha. Não houve diferença na proporção do peso carregado horizontalmente entre as classes de tamanho (pequenos: $0,49 \pm 0,48$ g, médios: $0,37 \pm 0,07$ mg, grandes: $0,5 \pm 0,3 \mathrm{mg}$ ). Na posição vertical, foi suportado até 6,7 vezes o peso do animal e proporcionais ao tamanho dos moluscos (pequenos: 2,13 $\pm 0,6 \mathrm{mg}$, médios: 3,61 $\pm 0,24 \mathrm{mg}$, grandes: 5,5 $\pm 0,48 \mathrm{mg}$ ) (Anova $\mathrm{F}=119 ; \mathrm{p}<0,01$ ), porém não ocorreu deslocamento pela parede. A proporção de peso carregado horizontalmente $(0,46 \pm 0,3 ; \mathrm{n}=90$; i.v. $=0-1,25)$ foi significativamente menor do que suportado verticalmente $(3,7$ $\pm 1,6 ; \mathrm{n}=93 ;$ i.v. $=1,25-6,7)\left(\mathrm{t}_{184}=-19 ; \mathrm{p}<0,001\right)$.

\section{Resistência a métodos populares de controle}

O tempo máximo de resistência à água salobra foi de cinco horas $\left(\chi_{(1)}^{2}=54,4 ; \mathrm{p}<0,01\right)$ e à água doce de 20 horas $\left(\chi_{(1)}^{2}=\right.$ $74,7 ; \mathrm{p}<0,01)$, não houve diferenças na freqüência do número de animais que saíram da água entre as classes de tamanho no final do período de observação $\left(\chi_{(2)}^{2}=27,8\right.$; $\mathrm{p}<0,01$; Fig. 3). Nas primeiras cinco horas de monitoramento ininterrupto na água doce, os animais de tamanho mediano demoraram mais para deixar a água $\left(\chi_{(1)}^{2}=4,8 ; \mathrm{p}<0,01\right)$, enquanto que na água salobra foram os grandes $\left(\chi_{(1)}^{2}=6,5 ; p<0,01\right.$; Fig. 3$)$. Os animais que conseguiram deixar tanto a água doce quanto a salobra conseguiram sobreviver.

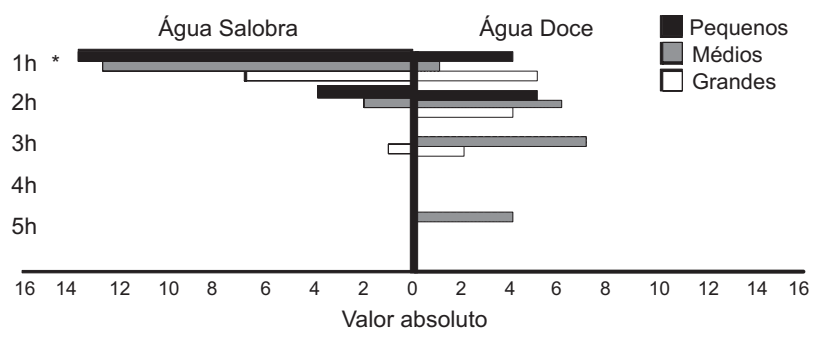

Figura 3. Número absoluto de caramujos pequenos, médios e grandes que saíram da água salobra e doce nos intervalos de uma a cinco horas. As diferenças significativas $(p<0,05)$ estão representadas pelo asterisco $\left(^{*}\right)$.

Achatina fulica apresentou pequena resistência ao sal, uma vez que ao serem colocados dentro do círculo de sal, todos os moluscos se recolheram na concha e não o ultrapassou (pequenos - $3 \mathrm{~cm}$ : 90\% e $10 \mathrm{~cm} \mathrm{1 \% ;} \mathrm{médios} \mathrm{-} 3$ cm: 50\%, 10 cm: 30\%, 15 cm: 20\%; grandes - 3 cm: 20\%, 10 cm: 40\%, 15 cm: 30\%, 20 $\mathrm{cm}: 10 \%)$. Porém, a maioria dos caramujos pequenos se recolheu a uma distância de aproximadamente $3 \mathrm{~cm}$ do sal $\left(\chi_{(2)}^{2}=\right.$ $6,4 ; \mathrm{p}<0,05)$, para animais medianos e grandes não houve diferenças nas proporções de animais que pararam a 3, 10, 15 e $20 \mathrm{~cm}$ do sal. Ao ser adicionado sal no pé, nenhum dos 30 indivíduos testados sobreviveu.

\section{DISCUSSÃO}

A espécie $A$. fulica, tradicionalmente considerada resistente aos fatores abióticos e com uma grande capacidade adaptativa, apresentou diferentes reações aos estímulos testados, os quais variaram de acordo com o estágio de desenvolvimento e a natureza do estímulo.

Os ovos de $A$. fulica foram pouco resistentes à alteração das condições abióticas testadas e, provavelmente, à manipulação, caracterizando o momento mais frágil do desenvolvimento do animal. MEAD (1961) apresenta alguns estudos com resultados similares, em que ovos foram susceptíveis principalmente às baixas temperaturas. De acordo com sua estratégia reprodutiva, $A$. fulica é caracterizada como r-estrategista, uma vez que oviposita muito ovos (em torno de 200 ovos por postura) de pequeno tamanho e baixa alocação de energia (RAUT \& BARKER 2002), logo sendo esperadas grandes perdas. No entanto, a espécie pode usar estratégias para minimizar a ação de condições ambientais no desenvolvimento embriológico. A forma como são depositados os ovos na terra pode aumentar as chances de eclosão, uma vez que enquanto parte dos ovos fica enterrada em profundidades de cerca de $6 \mathrm{~cm}$ a outra parte tampa a entrada dessa cavidade. Este padrão sugere que os ovos que ficam na superfície sirvam como proteção, muitas vezes não se desenvolvendo, porém promovendo condições abióticas mais estáveis para os ovos do interior. Outra estratégia que também pode maximizar a viabilidade dos ovos e protegê-los da instabilidade climática e ausência de substratos adequados é a retenção de ovos fertilizados e com cascas e a liberação dos mesmos em estágios avançados de desenvolvimento (PAWson \& Chase 1984), muitas vezes um dia antes da eclosão. No presente estudo foi evidenciado que o tipo de substrato e sua condição de umidade são importantes na eclosão dos ovos. No entanto, a capacidade adaptativa da espécie é refletida no fato de terem ocorrido eclosões, mesmo que em baixa freqüência, em substratos com grande concentração de sal e em substratos com baixa concentração de umidade. Levando à expectativa que mesmo que a freqüência de eclosão seja baixa, os poucos ovos que conseguem se desenvolver podem viabilizar a manutenção da espécie no ambiente.

A baixa eclosão dos ovos enterrados e permanência dos filhotes sob a terra até duas semanas após a eclosão podem ser interpretadas através da comparação com a disposição da postura observada em animais livres, em que pouca ou nenhuma terra é depositada sobre os ovos superiores. Logo, a pressão exercida pela terra pode ter influenciado na eclosão e inviabilizado o desenterramento dos animais. Também é possível que os recém- 
eclodidos permaneçam as semanas iniciais de sua vida protegidos sob o substrato e só, depois, comecem a dispersar. Pawson \& CHASE (1984) observaram em laboratório que o período de permanência enterrado varia de quatro a sete dias, enquanto que em campo, RAUT \& BARKER (2002) verificaram que varia de cinco a 15 dias. A adoção desse comportamento pelos filhotes da $A$. fulica deve ser considerado em planos de manejo que usam a catação manual dos animais como método de controle, e um alerta de que a mesma deve ser contínua. Simião \& Fischer (2004) verificaram uma re-colonização de $19 \%$ da população após três meses da coleta de todos os indivíduos visíveis em um terreno no litoral do Paraná, sendo os animais remanescentes representados principalmente por indivíduos pequenos, provavelmente resultantes de filhotes recém-eclodidos, os quais estavam enterrados no momento do controle.

A ausência de produção do epifragma no período de $24 \mathrm{~h}$ nas temperaturas em que a $A$. fulica foi submetida, sem aquecimento ou resfriamento gradual, sugere que os animais necessitem de determinado período formá-lo (MEAD 1961). Embora, segundo Struthers et al. (2002), esse período possa ser curto, pois a fase inorgânica de reforço do epifragma é pré-produzida e codepositada na matriz do muco. A mortalidade nas temperaturas baixas indica a maior sensibilidade dos animais a essas condições, principalmente quando as mudanças são repentinas podendo ser fatais, correspondendo com a baixa ocorrência da espécie em locais com invernos mais rigorosos (Teles \& Fontes 1998, RAUT \& BARKER 2002) e com o fato dos animais estivarem no inverno no litoral sul do Brasil (FIscher \& ColLey 2004, 2005).

A estratégia do caramujo de estivar ao se enterrar permite que os animais permaneçam sob a terra por um longo período se protegendo de condições ambientais desfavoráveis. No entanto, devem-se considerar a importância das características físicas e químicas do solo, como compactação e capacidade de retenção de água (PACHeco et al. 1998), uma vez que segundo RAut \& Chose $(1977,1981)$, a mortalidade durante a estivação é alta (46\%), principalmente se o período seco for muito longo e o animal velho. Assim, a detecção do momento da saída do estado de estivação é tão importante quanto a entrada, havendo uma relação desse mecanismo com o estágio de desenvolvimento, sendo os animais grandes mais predispostos a reagirem a estímulos como queda de temperatura e presença de alimentos. Porém, o aumento de umidade foi o fator mais importante, dentre os testados como indicativos para o animal sair do estado de estivação. Segundo Raut \& Chose (1977), A. fulica possui adaptação para tal, uma vez que seu epifragma apesar de impermeável, possui uma pequena rachadura que mantém o contanto entre pneumóstoma e o ambiente externo. Desta forma, a abertura da concha é direcionada para baixo, de modo o ar existente entre o epifragma e o solo condense com o aumento da umidade externa, uma vez que se torna mais frio que o ar da superfície, indicando, assim, para o caramujo, o momento da saída da estivação. Subsidiando a importância da concentração de umidade, foi verificado no presente estudo que a água borrifada em pequenas quantidades não foi tão efetiva quanto a submersão em água, principalmente nos animais de maior tamanho. A proteção do epifragma contra a evaporação causada pelo calor e falta de umidade é efetiva mesmo em animais que estivam em superfícies verticais e expostos no ambiente (Struthers et al. 2002), como no observado em animais livres em Guaraqueçaba. A eficiência do epifragma é tão significativa que pode proteger o animal mesmo do contato direto com o sal. Esse resultado é um alerta para ações de manejo que usam o sal no controle dos animais, uma vez que não terá efeito caso esteja estivando. Deve-se considerar, também, que o enterramento é uma estratégia de defesa, contra fatores abióticos e bióticos, importante principalmente em animais jovens e embora o processo demore alguns dias e o animal não alcance grandes profundidades, pode passar despercebido nos programas de controle representando animais re-colonizadores como no observado no município de Pontal do Paraná por SIMIÃo \& Fischer (2004).

A grande resistência de $A$. fulica ao meio aquático, tanto dulcícola como salobra, verificada também por MEAD (1961), leva a expectativa que a espécie possa ser capaz de utilizar a correnteza de rios como forma de dispersão. É possível também que seja um mecanismo adaptativo para situações de alagamento do sítio de repouso ou de estivação, o que comumente deve ocorrer, uma vez que freqüentemente se enterram nas bases de muros e árvores. Segundo MEAD (1961), é alta a mortalidade decorrente de alagamentos rápidos em que o animal não tenha chance de deslocamento vertical. Esse mecanismo também é um alerta para as autoridades incumbidas de orientar a população quanto aos destinos a serem dados aos animais capturados. Mesmo em água salobra, o período de cinco horas pode ser suficiente para um caramujo conseguir sair da água se fixando em um barco ou sendo carregado pela correnteza. Inclusive, MEAD (1961) apresenta relatos de autores que verificaram a sobrevivência de caramujos jogados em águas oceânicas. A baixa resistência ao sal e o fato do animal não atravessar uma barreira de sal, pode ser tomado como indicativo da eficiência desse produto, embora devam ser consideradas questões como a influência negativa do sal sobre a fauna e flora nativas.

Assim, a resistência da espécie invasora $A$. fulica a fatores abióticos está relacionada com o estágio de desenvolvimento e natureza do estímulo. Os ovos foram caracterizados pela fase mais susceptível, enquanto jovens e adultos foram resistentes à submersão em água doce e salobra e pouco resistentes a variação de temperatura e ao sal, usando como estratégia de defesa o enterramento, a estivação e a força muscular. Essas estratégias devem ser consideradas em ações de manejo e na orientação para utilização de métodos populares de controle.

\section{AGRADECIMENTOS}

À Pró-reitoria de Pesquisa e Extensão da Pontifícia Universidade Católica do Paraná, à Bolsista PIBIC/PUCPR Domitila Bonato e à equipe do NEC-PUCPR. 


\section{LITERATURA CITADA}

Alowe, S.; M. Browne \& S. Boudjelas. 2004. 100 of the world's worst invasive alien species. A selection from the global invasive species database. Avalaible online at: www.issg.org/ database [Accessed: 05.VIII.2008]

Civeyrel, L. \& D. Simberloff. 1996. A tale of two snails: is the cure worse than the disease? Biodiversity and Conservation 5: 1231-1252.

D'Ávila, S.; R.J.P. Dias; E.C. Bessa \& E. DAEmon. 2004. Resistência à dessecação em três espécies de moluscos terrestres: aspectos adaptativos e significado para o controle de helmintos. Revista brasileira de Zoociências 6 (1): 115-127.

Fischer, M. L. \& E. Colley. 2004. Diagnóstico da ocorrência do caramujo gigante africano Achatina fulica Bowdich, 1822 na APA de Guaraqueçaba, Paraná, Brasil. Estudos de Biologia 26: $43-50$.

Fischer, M. L. \& E. Colley. 2005. Espécie invasora em reservas naturais: caracterização da população de Achatina fulica Bowdich, 1822 (Mollusca - Achatinidae) na Ilha Rasa, Guaraqueçaba, Paraná. Biota Neotropica 5: 1-18.

Hodasi, J.K.M. 1979. Life-History studies of Achatina (Achatina) achatina (Linné). Journal of Molluscan Studies 45: 329-339.

MEAD, A.R. 1961. The giant african snail: a problem in economic malacology. Chicago, University of Chicago, 194p.

Pacheco, P.; M.F. Martins; M. Luches; S.A. Ribeiro; A. Spers \& P.H.M. Rodrigues. 1998. Estudo do desempenho ponderal do escargot Achatina fulica em diferentes tipos de solo. Arquivos do Instituto Biológico 65: 9-12.
PAWsON, P.A. \& R. CHASE. 1984. The life-cycle reproductive activity of Achatina fulica (Bowdich) in laboratory culture. Journal of Molluscan Studies 50: 85-91.

RAUT, S.K. \& G.M. BARKER. 2002. Achatina fulica Bowdich and other Achatinidae as Pests in Tropical Agriculture, p. 55114. In: G.M. BARKer (Ed.). Molluscs as Crop Pests. New Zealand, Ed. CAB Publishing, 576p.

RauT, S.K. \& K.C. CHose. 1977. Effect of upwardly-directed shell aperture on the aestivating land snail Achatina fulica. Nautilus 91: 31-32.

Raut, S.K. \& K.C. Chose. 1981. Factors influencing mortality in land snails, Achatina fulica Bowdich and Macrochlamys indica Godwin-Austen during aestivation. Proceedings of the Zoological Society of London 32: 107-120.

Simĩ̃o, M.S. \& M.L. Fischer. 2004. Estimativa e inferências do método de controle do molusco exótico Achatina fulica Bowdich 1822 (Stylommatophora; Achatinidae) em Pontal do Paraná, litoral do Estado do Paraná. Cadernos de Biodiversidade 4: 74-82.

Struthers, M.; G. Rosair; J. Buckman \& C. Viney. 2002. The physical and chemical microstructure of the Achatina fulica epiphragm. Journal of Molluscan Studies 68: 165-171.

Teles, H.M.S. \& L.R. FonTEs. 1998. Escargot: mais um perigo à mesa. Nova Ameaça à saúde pública e à agricultura. Revista Vetores e Pragas 1: 4-8.

Tomiyama, K. 1996. Mate-choice criteria in a protandrous simultaneously hermaphroditic snail Achatina fulica (Férussac) (Stylommatophora: Achatinidae). Journal of Molluscan Studies 62: 101-111.

Submitted: 13.XI.2008; Accepted: 25.VIII.2009.

Editorial responsibility: Walter A.P. Boeger 